\title{
Article
}

\section{TEOS-Based Superhydrophobic Coating for the Protection of Stone-Built Cultural Heritage}

\author{
Fotios G. Adamopoulos ${ }^{1,2}$, Evangelia C. Vouvoudi ${ }^{1}$, Eleni Pavlidou ${ }^{3}$, Dimitris S. Achilias ${ }^{1, *(D)}$ and \\ Ioannis Karapanagiotis $2, * \mathbb{D}$ \\ 1 Laboratory of Polymers and Dyes Chemistry and Technology, Department of Chemistry, \\ Aristotle University of Thessaloniki, GR-54124 Thessaloniki, Greece; r2r5r1r5r7@yahoo.gr (F.G.A.); \\ evouvoud@chem.auth.gr (E.C.V.) \\ 2 Department of Management and Conservation of Ecclesiastical Cultural Heritage Objects, \\ University Ecclesiastical Academy of Thessaloniki, GR-54250 Thessaloniki, Greece \\ 3 Department of Physics, Aristotle University of Thessaloniki, GR-54124 Thessaloniki, Greece; elpavlid@auth.gr \\ * Correspondence: axilias@chem.auth.gr (D.S.A.); y.karapanagiotis@aeath.gr (I.K.)
}

Citation: Adamopoulos, F.G.; Vouvoudi, E.C.; Pavlidou, E.; Achilias, D.S.; Karapanagiotis, I. TEOS-Based Superhydrophobic Coating for the Protection of Stone-Built Cultural Heritage. Coatings 2021, 11, 135. https://doi.org/10.3390/ coatings11020135

Academic Editor: Mara Camaiti Received: 17 December 2020

Accepted: 21 January 2021

Published: 27 January 2021

Publisher's Note: MDPI stays neutral with regard to jurisdictional claims in published maps and institutional affiliations.

Copyright: (c) 2021 by the authors. Licensee MDPI, Basel, Switzerland. This article is an open access article distributed under the terms and conditions of the Creative Commons Attribution (CC BY) license (https:// creativecommons.org/licenses/by/ $4.0 /)$.

\begin{abstract}
Tetraethyl orthosilicate (TEOS) is extensively used in the conservation of stone-built cultural heritage, which is often subjected to water-induced degradation processes. The goal of this study was to produce and study a TEOS-based material with the ability to repel liquid water. A sol solution of TEOS and $1 \mathrm{H}, 1 \mathrm{H}, 2 \mathrm{H}, 2 \mathrm{H}$-perfluorooctyl triethoxysilane (FAS) was prepared and deposited on marble. The static contact angles (CAs) of water drops on the coated marble surface were $>170^{\circ}$ and the sliding angles (SA) were $<5^{\circ}$, suggesting that superhydrophobicity and water repellency were achieved on the surface of the synthesized TEOS-based coating. FTIR and SEM-EDS were employed to characterize the produced coating. The latter offered good protection against water penetration by capillarity, reducing the breathability of marble only by a small extent and with practically no effect on its aesthetic appearance. The durability of the coating was evaluated through various tests that provided very promising results. Finally, the versatility of the method was demonstrated as the TEOS-based coating was successfully deposited onto glass, brass, wood, silicon, paper and silk, which obtained extreme wetting properties.
\end{abstract}

Keywords: superhydrophobic; TEOS; silane; cultural heritage; marble; conservation

\section{Introduction}

Wear and degradation of natural stone in buildings and objects of cultural heritage originate naturally from the effects of atmospheric water (rain and humidity), temperature and light. Other factors such as dust, soot, fungi and various microorganisms contribute to the wear process. Damage is also caused by the absence of appropriate protection measures and careless handling. Atmospheric pollutants such as $\mathrm{SO}_{2}$ and $\mathrm{NO}_{x}$, which are byproducts of the combustion of hydrocarbons, cause corrosion in monuments of stone or metal [1].

Alkoxysilanes are widely applied materials for stone consolidation and protection, mainly due to their low viscosity, which allows the materials to penetrate deep into the interior of the stones, forming polysiloxane networks [2]. Tetraethyl orthosilicate (TEOS) is the base of most commercial products which, after their application, are polymerized in situ through a sol-gel process, improving the mechanical strength of materials and carrying characteristics of hydrophobicity [2-4].

Fluorinated polymers consist of another interesting family of materials that can contribute to the conservation of natural stone. Fluorinated polymers have interesting properties, since replacing the $\mathrm{H}$-atoms with F-atoms does not change significantly the mobility of macrochains or the stereochemical inhibition of the macromolecule. The high electronegativity of F-atoms in the bond $\mathrm{C}-\mathrm{F}\left(\chi_{\mathrm{F}}=3.98, \chi_{\mathrm{C}}=2.55\right)$ gives a significant dipole, while the electrostatic attraction makes $C-F$ an unusually strong bond $\left(\Delta H_{d}=544 \mathrm{~kJ} / \mathrm{mol}\right)$. As a 
result, high thermal and chemical stability, small values of dielectric constant, refractive index, surface energy and flammability, and repellent action in water and oils characterize fluorinated polymers [5].

In the present study, a material was produced using a silica sol solution prepared through the co-hydrolysis and condensation of TEOS and a fluorinated agent $(1 \mathrm{H}, 1 \mathrm{H}, 2 \mathrm{H}, 2 \mathrm{H}-$ perfluorooctyl triethoxysilane, FAS) [6]. The main objective of this study was to investigate the interactions of marble treated with the TEOS-FAS material and liquid water, which can cause direct (e.g., through freezing-thawing cycles) or indirect (e.g., by the deposition of pollutants) degradation effects in cultural heritage monuments, buildings, and objects. The introduction of FAS in the recipe induced superhydrophobic and water-repellent properties to the TEOS-based material. Superhydrophobicity and water repellency were evidenced by the large static $\left(\mathrm{CA}>170^{\circ}\right)$ and low sliding $\left(\mathrm{SA}<5^{\circ}\right)$ contact angles of water drops on the coated marble surface. These extreme, non-wetting properties are highly desirable for their ability to reduce the rate of water-induced degradation in natural stone. For this reason, several investigations have been carried out in the last decade to impart enhanced hydrophobicity $\left(120^{\circ}<\mathrm{CA}<150^{\circ}\right)$ [7-26] or, even better, superhydrophobicity $\left(\mathrm{CA}>150^{\circ}\right)$ [27-44] onto stone surfaces. However, in most of these previously published reports, nanoparticles have been used that were made of silicon $[8,11,17,23,24,27,28,30,31,35,36,38-41,43]$, titanium $[19,20,22,28,29,32,34,37,38]$, zinc [26,32,36], aluminum [28] or tin [28] oxide, as well as silver [13,42] and calcium hydroxide [44]. Nanoparticles have been added into low surface energy polymers to induce (i) enhanced roughness, which is a key factor in achieving a non-wetting state [45], and (ii) other useful properties such as self-cleaning and biocide activity, which are beyond the scope of our study. As the technological applications of nanoparticles increase rapidly, concerns have been raised about the potential health and environmental risks associated with the use of these nanomaterials [46]. In some studies, enhanced hydrophobization of inherent hydrophilic natural stones was achieved without using nanoparticles $[7,9,10,12,14-16,18,21,25]$. However, nanoparticle-free superhydrophobic and water-repellent materials have rarely been produced for the conservation of natural stone [33].

In the present study, extreme wetting properties on coated marble were achieved without engineering nanoparticles. Attention is focused on marble, but the versatility of the method is demonstrated as the TEOS-based coating is successfully deposited on other materials, obtaining superhydrophobic and water-repellent properties.

\section{Materials and Methods}

\subsection{Materials}

The following materials were used for the preparation of the coatings: tetraethyl orthosilicate (98\%) $\left(\mathrm{C}_{8} \mathrm{H}_{20} \mathrm{O}_{4} \mathrm{Si}\right.$ ) (TEOS, CAS 78-10-14, Sigma Aldrich, St. Louis, MO, USA), $1 \mathrm{H}, 1 \mathrm{H}, 2 \mathrm{H}, 2 \mathrm{H}$-perfluorooctyl triethoxysilane $(97 \%)\left(\mathrm{C}_{14} \mathrm{H}_{19} \mathrm{~F}_{13} \mathrm{O}_{3} \mathrm{Si}\right)$ (FAS, CAS 51851-37-7, Sigma Aldrich, St. Louis, MO, USA), aqueous solution of ammonium hydroxide $\left(\mathrm{NH}_{4} \mathrm{OH}\right)$ (25\%, CAS 1336-21-6, Scharlau Chemie SA, Barcelona, Spain) and ethanol ( $\left.\mathrm{EtOH}, \mathrm{C}_{2} \mathrm{H}_{5} \mathrm{OH}\right)$ ( $>98 \%$, CAS 64-17-5 Chem Lab, Zedelgem, Belgium).

The following materials were purchased from the local market and used as substrates for coating deposition: blocks of white (Thassos) marble and beech wood, glass slides, filter paper (Whatman $\mathrm{N}^{\circ} 4$ ), polished brass specimens and silk. Moreover, silicon (Si) wafers were included in the study, and these were obtained from Siegert Wafer (Aachen, Germany).

Except for silk and paper, substrate materials were washed with tap water then rinsed with deionized water and acetone. They remained in ambient conditions for 4 days in order to dry, while for total moisture removal the specimens were placed in a Thermconcept oven (KL 15/12) for $48 \mathrm{~h}$ at $80^{\circ} \mathrm{C}$, then left to cool. Blocks of marble and wood with dimensions of $5 \mathrm{~cm} \times 5 \mathrm{~cm} \times 2 \mathrm{~cm}$ and $2 \mathrm{~cm} \times 2 \mathrm{~cm} \times 2 \mathrm{~cm}$, respectively, were used. The relative atomic composition of brass was $62.6 \% \mathrm{Cu}, 35.4 \% \mathrm{Zn}$ and $2 \%$ other metals, according to $\mathrm{X}$-ray fluorescence (XRF) results [43]. 


\subsection{Synthesis and Deposition of Coatings}

The procedure for preparing of the coating was adapted from Wang et al. [6]. Two solutions were prepared: (i) $5 \mathrm{~mL}$ of TEOS and $1.15 \mathrm{~g}$ of FAS (FAS/TEOS: 1/10) were dissolved in $25 \mathrm{~mL}$ EtOH and stirred at room temperature for $1 \mathrm{~h}$; (ii) $\mathrm{NH}_{4} \mathrm{OH}$ solution $(7 \mathrm{~mL})$ was diluted in $25 \mathrm{~mL} \mathrm{EtOH}$ and stirred at room temperature for $1 \mathrm{~h}$. The two solutions were mixed in an Erlenmeyer flask and stirred for $12 \mathrm{~h}$ (ARE Heating Magnetic System, VELP Scientifica, Usmate Velate, Italy) then placed in an ultrasonic bath (Elmasonic S15h, ELMA, Singen, Germany) for $30 \mathrm{~min}$ at room temperature.

The white sol-solution was deposited onto marble specimens by brush, spray, and dip coating. The three facile techniques were applied to investigate any potential effects of the coating deposition technique on the wettability of the resulting TEOS-FAS surface. The brush utilized was a Da Vinci Forte Basic No. 4. Six brush stokes were applied, with each covering being applied to the opposite direction of the previous one after the previous one had dried. The airbrush system (Paasche Airbrush, Chicago, IL, USA)) was operated using a nozzle that was $660 \mu \mathrm{m}$ in diameter, as described in detail elsewhere [35,43,44]. For the dip coating process, marble samples were partially immersed by $1 \mathrm{~cm}$ in the sol-solution for $50 \mathrm{~h}$. After coating deposition, the marble samples were left to dry for $24 \mathrm{~h}$ at room temperature, then further cured at $110{ }^{\circ} \mathrm{C}$ for $24 \mathrm{~h}$ and finally left to cool.

Coatings on glass, brass, Si wafers, paper and silk were applied by brush, whereas the dip coating method was applied to treat wood. The latter is a porous material and for this reason the dip coating method was selected to ensure good coverage of the wood via the TEOS-FAS material.

Dry coated and uncoated samples were weighted to measure the coating uptake.

\subsection{Instruments and Characterization Tests}

Marble samples were examined using a JEOL (Tokyo, Japan) scanning electron microscope (JSM-6390LV) equipped with an energy-dispersive X-ray (EDS) INCA microanalytical system and X-ray Diffraction (XRD) (Rigaku Mini Flex II, Tokyo, Japan). Operating conditions of SEM were an accelerating voltage of $20 \mathrm{kV}$ and a probe current of $45 \mathrm{nA}$, while the working distance was set at $10 \mathrm{~mm}$. Samples were coated using a JEOL JEE- $4 \mathrm{X}$ vacuum evaporator. For the XRD studies, marble was powdered and examined using a $\mathrm{Cu} K \alpha$ ray $(\lambda=0.154 \mathrm{~nm})$ with range of $2 \theta$ angle $10^{\circ}-80^{\circ}$. The results regarding the characterization of the marble specimens are provided in Figures S1 and S2 in the Supplementary Materials.

SEM-EDS was also used to study the chemical composition and the morphology of the surface of coated marble. The FTIR (Spectrum One, Perkin Elmer, Waltham, MA, USA) spectroscopy was employed to study the TEOS-FAS sol, working with $\mathrm{NaCl}$ window crystals at $4000-400 \mathrm{~cm}^{-1}, 32$ scans, and a resolution of $4 \mathrm{~cm}^{-1}$.

Three drops of distilled water were placed at three different spots on coated substrates. Static (CA) and sliding (SA) contact angles were measured using an optical tensiometer apparatus (Attension Theta, Gothenburg, Sweden). For the measurements of the SAs, the tilt rate was adjusted to $1^{\circ} / \mathrm{s}$. The reported contact angles are averages of five measurements. Colorimetric measurements were carried out using a MiniScan XE Plus spectrophotometer (HunterLab, Reston, VA, USA) and the results were evaluated using the $L^{*}, a^{*}, b^{*}$ coordinates of the CIE 1976 scale. The reported results are averages of three measurements. The silane uptake was measured gravimetrically (Sartorius, Göttingen, Germany).

Six more tests were carried out on marble that was treated using the dip coating method. For water absorption, the capillary effect was utilized in which the pre-weighted marble specimen was placed with the coated side downwards into a vessel with distilled water for $1 \mathrm{~h}$ at ambient conditions. The weight was then recorded every $5 \mathrm{~min}$ for the next hour, after gently removing the extra moisture from the coated surface.

As for the vapor permeability test, marble specimens were placed on top of an Erlenmeyer flask containing $100 \mathrm{~mL}$ of distilled water and sealed with parafilm. The specimen was placed so that the coated surface was facing water. The flasks were placed in a Heraeus 
oven (Thermo Scientific, USA) at $40{ }^{\circ} \mathrm{C}$ and $\mathrm{RH}=25 \%$, then weighted every $24 \mathrm{~h}$ for 3 consecutive days to calculate the vapor permeability.

To evaluate the stability of the treatment, coated marble was immersed in a water bath for $48 \mathrm{~h}$ in total. The sample was periodically removed from the bath and contact angles were measured. Moreover, drops of solutions, which were prepared using hydrochloric acid $(\mathrm{HCl}, \mathrm{ChemLab})$ and sodium hydroxide $(\mathrm{NaOH}$, In Situ, Thessaloniki, Greece) that corresponded to a wide $\mathrm{pH}$ range, were placed on coated marble and contact angles were measured.

The following procedure was applied to investigate the effects of salt crystallization: a coated marble specimen was immersed in a saturated solution of sodium sulfate $\left(\mathrm{Na}_{2} \mathrm{SO}_{4}\right.$, Merck, Kenilworth, NJ, USA) for $4 \mathrm{~h}$. The sample was removed from the bath, left at ambient conditions for $28 \mathrm{~h}$, and placed in the oven $\left(105^{\circ} \mathrm{C}\right)$ for $1 \mathrm{~h}$. The above procedure was repeated three more times. Contact angles were then measured.

Finally, coated marble samples were exposed to outdoor conditions for 70 days in the urban environment of the coastal city of Thessaloniki, Greece, where the temperature and relative humidity ranges were $4-33^{\circ} \mathrm{C}$ and $19-100 \%$, respectively.

\section{Results}

\subsection{Characterisation of the TEOS-FAS Sol and Coating}

The spectrum for the TEOS-FAS sol is shown in Figure 1, where we can observe the wide and intensive $3345 \mathrm{~cm}^{-1}$ peak corresponding to $\mathrm{O}-\mathrm{H}$ absorbance (solvent and silane) and the $2974-2889 \mathrm{~cm}^{-1}$ intensive sharp peaks corresponding to the asymmetric and symmetric stretch vibrations of the C-H bonds $\left(s p^{3}\right)$ at the left part of the spectrum [47-50]. To the right, we see a sharp medium-height peak of $1654 \mathrm{~cm}^{-1}$ in regards to the scissoring vibration of the N-H bond. The group of peaks at $1451-1388 \mathrm{~cm}^{-1}$, medium and sharp in shape, corresponds to the asymmetric and symmetric stretches of $\mathrm{C}-\mathrm{H}$ bonds in $-\mathrm{CH}_{2}-$ groups [50,51], along with stretching vibration of $\mathrm{C}-\mathrm{F}$ in the $-\mathrm{CF}_{2}-\mathrm{CF}_{3}$ groups [52-54]. The small peak at $1270 \mathrm{~cm}^{-1}$ is a result of the $\mathrm{Si}-\mathrm{C}$ vibrations in the $\mathrm{Si}-\mathrm{CH}_{3}$ group and the shoulder at $1194 \mathrm{~cm}^{-1}$ indicates the presence of $\mathrm{C}-\mathrm{F}$ bonds corresponding to the stretches of $>\mathrm{CF}_{2}$ bonds [54-58]. The detection of $\mathrm{C}-\mathrm{F}$ bonds is hard, due to the overlap with other simple bonds of $\mathrm{C}$ atoms. The long sharp peak at $1089 \mathrm{~cm}^{-1}$ corresponds to the $\mathrm{Si}-\mathrm{O}-\mathrm{Si}$ bond, while a bit lower the $1051 \mathrm{~cm}^{-1}$ peak corresponds to the $\mathrm{C}-\mathrm{O}$ contained in EtOH and silanes $[50,51,55,59,60]$. In the fingerprint region, the large sharp peak at $891 \mathrm{~cm}^{-1}$ reveals the deformation of the $\mathrm{C}-\mathrm{H}$ bonds in $-\mathrm{CH}_{3}$ of $\mathrm{EtOH}$, and the smaller peak at $958 \mathrm{~cm}^{-1}$ denotes the rocking $\mathrm{C}-\mathrm{H}$ of silanes $-\mathrm{CH}_{3}$ [48]. The small absorption in $802 \mathrm{~cm}^{-1}$ corresponds to the $\mathrm{Si}-\mathrm{O}$ stretching bonds $[47,55,59]$.

Finally, the surface of the coated marble was investigated using SEM-EDS. Spectra were acquired from several points of the sample surface. Examples from this study are provided in the Supplementary Materials. Elevated concentrations of silicon (Si) and fluorine $(\mathrm{F})$ were recorded, suggesting a uniform coverage of marble by TEOS-FAS. Other elements recorded at elevated concentrations were calcium $(\mathrm{Ca})$, magnesium $(\mathrm{Mg})$, and oxygen $(\mathrm{O})$ that originated from the marble substrate, as shown in Figure S3 in the Supplementary Materials.

\subsection{TEOS-FAS Coating on Various Substrates: Wettability and Colorimetry}

Table 1 shows the results of the static contact angle (CA) and sliding angle (SA) measurements of water drops on the TEOS-FAS coatings that were deposited on various substrates. Superhydrophobicity and water repellency were obtained on every coated material, as evidenced by the extremely large CA $\left(>160^{\circ}\right)$ and low SA $\left(<7^{\circ}\right)$. Consequently, the TEOS-FAS coating could be applied on a large variety of materials to induce extreme, non-wetting properties. The same conclusion was reported by Wang et al., who were primarily interested in inducing superhydrophobicity onto fabrics [6]. Glass and $\mathrm{Si}$ wafers were used as substrate materials in both that study [6] and the present investigation, and can be therefore used for comparison, with an excellent agreement between the two studies. 
According to Wang et al., CA on coated glass and Si wafers were $174.6^{\circ}\left( \pm 1.6^{\circ}\right)$ and $174.2^{\circ}$ $\left( \pm 1.4^{\circ}\right)$, respectively, whereas the SA results reported for the same coated substrates were $2.3^{\circ}\left( \pm 0.3^{\circ}\right)$ and $2.4^{\circ}\left( \pm 0.2^{\circ}\right)$. These results are in agreement with the corresponding measurements in Table 1.

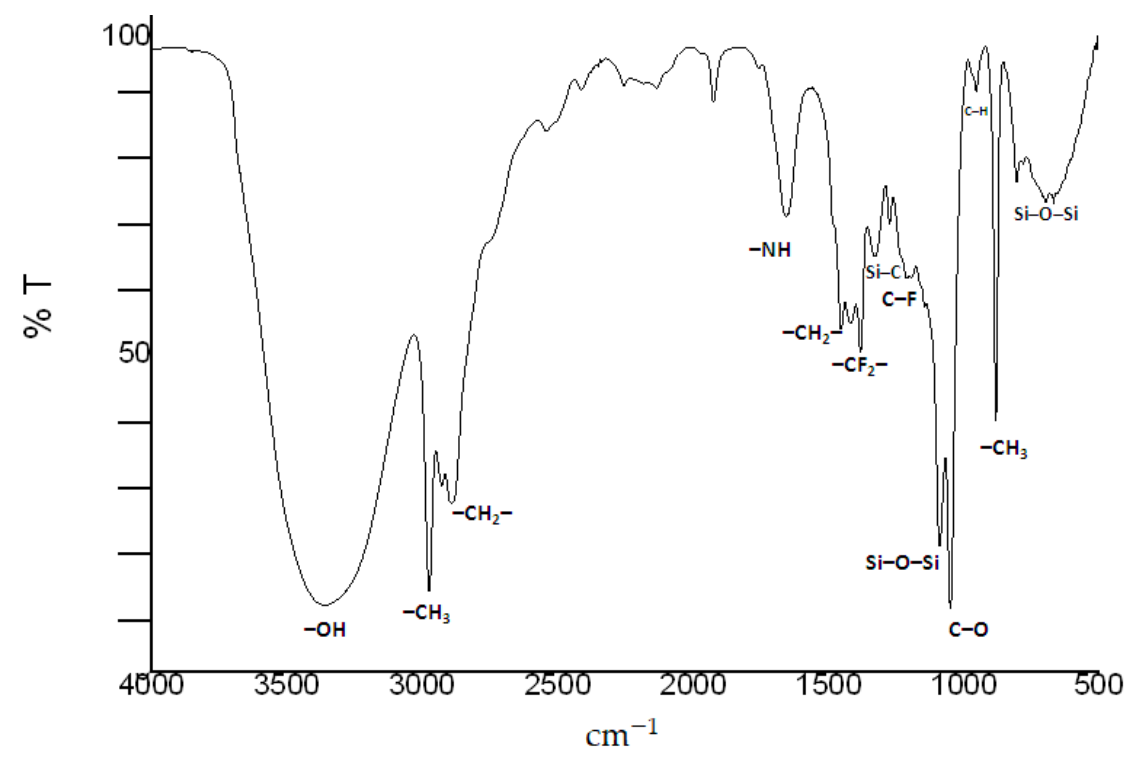

Figure 1. Spectrum of TEOS-FAS sol.

Table 1. Static contact angle (CA) and sliding angle (SA) of water drops on various coated substrates. The coating method and TEOS-FAS uptake after drying are reported.

\begin{tabular}{|c|c|c|c|c|}
\hline Substrate & Coating Method & $\begin{array}{c}\text { Uptake } \\
\text { (g of Coating/(cm }{ }^{2} \text { Substrate) }\end{array}$ & $\mathrm{CA}\left({ }^{\circ}\right)$ & SA $\left(^{\circ}\right)$ \\
\hline Marble & Brush coating & $0.0127 \pm 0.002$ & $172.5 \pm 2.7$ & $2.3 \pm 0.3$ \\
\hline Marble & Spray coating & $0.0080 \pm 0.001$ & $173.0 \pm 1.9$ & $4.2 \pm 0.4$ \\
\hline Marble & Dip coating & $0.1100 \pm 0.003$ & $171.5 \pm 2.7$ & $4.7 \pm 0.4$ \\
\hline Glass & Brush coating & $0.0056 \pm 0.002$ & $171.7 \pm 2.4$ & $3.7 \pm 0.1$ \\
\hline Brass & Brush coating & $0.0017 \pm 0.001$ & $167.6 \pm 1.1$ & $1.3 \pm 0.1$ \\
\hline Wood & Dip coating & $0.0436 \pm 0.005$ & $162.6 \pm 3.1$ & $2.6 \pm 0.2$ \\
\hline Si wafers & Brush coating & $0.0016 \pm 0.001$ & $168.5 \pm 3.0$ & $2.1 \pm 0.2$ \\
\hline Paper & Brush coating & $0.0014 \pm 0.0002$ & $162.8 \pm 1.8$ & $6.2 \pm 0.2$ \\
\hline Silk & Brush coating & $0.0014 \pm 0.0003$ & $166.9 \pm 2.9$ & $3.4 \pm 0.1$ \\
\hline
\end{tabular}

Focusing on the results reported for marble (Table 1), it can be concluded that the coating deposition method did not affect the wetting properties of the coating surface. CA and SA of water drops varied roughly within the same range on coatings that were deposited on marble using brush, the spraying system, and the dip coating method (Table 1). CA and SA were practically unaffected by the coating deposition method, despite the corresponding very large variations in the TEOS-FAS uptakes. The largest amount of TEOS-FAS was deposited on marble by the dip coating method, followed by brush and finally spray deposition. An order of magnitude difference in the TEOS-FAS uptakes for the dip and brush coating methods are reported in Table 1. Likewise, a major difference could be seen in the uptakes of TEOS-FAS deposited by brush and spray. However, as shown in Table 1, CA and SA on the marble specimens coated by the three deposition methods varied within only $171.5^{\circ}-173.0^{\circ}$ and $2.3^{\circ}-4.7^{\circ}$, respectively.

The results of Table 1 suggest, furthermore, that the substrate had only a minor effect on the wetting properties of the coating surface. CA and SA of drops deposited on various coated materials varied within roughly $10^{\circ}$ and $5^{\circ}$, respectively. The minor effect of the 
underlying substrate on the wetting properties of a superimposed superhydrophobic coating has been previously reported for the studied TEOS-FAS material by Wang et al. [6], for other siloxane polymers [33], and for polymer + nanoparticles composites [43,61].

The superhydrophobic and water-repellent character of the produced coating, as well as the versatility of the method employed to achieve extreme wetting properties on different substrates, is demonstrated in Figure 2. Water drops with nearly spherical shapes were placed on various coated substrates (Figure 2a-f). The surface structure of the produced coating on marble is revealed by the SEM image of Figure 2e. In order to demonstrate the easy/self-cleaning ability of the produced coating, the surface of a coated marble specimen was deliberately contaminated with particulates and slightly tilted. The particulates were easily removed by water drops which rolled off the tilting surface (Figure $2 \mathrm{~g}$ ).
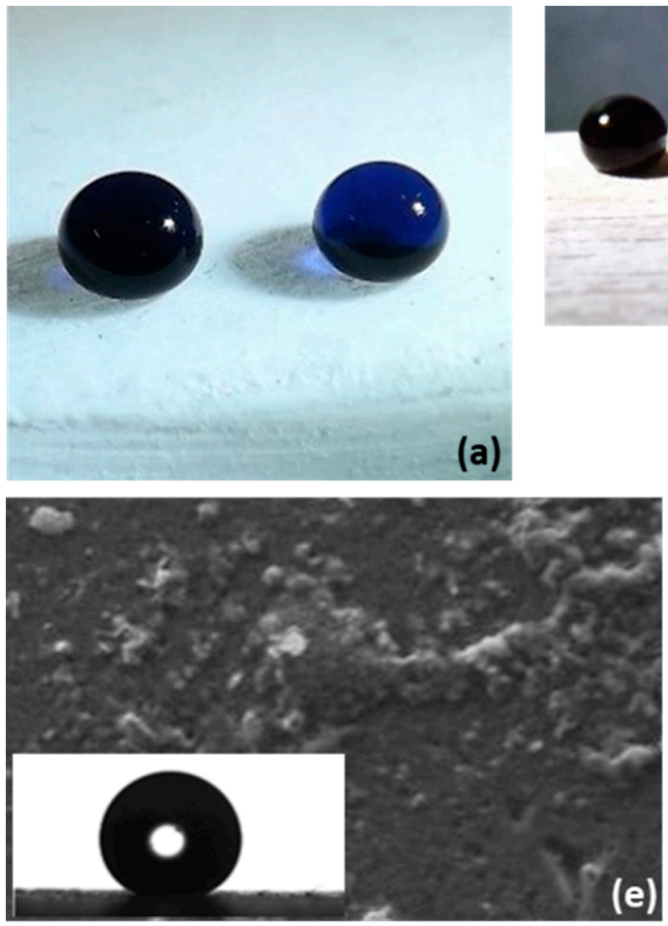

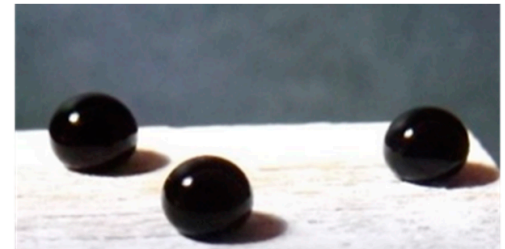

(b)
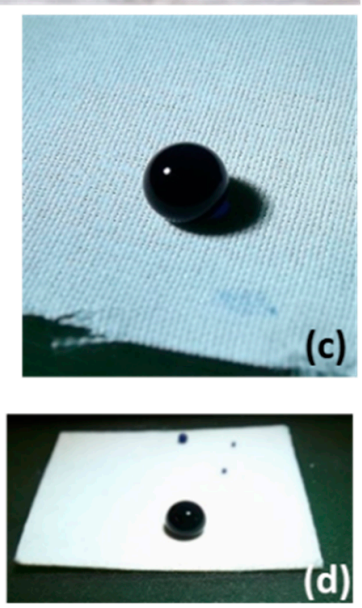

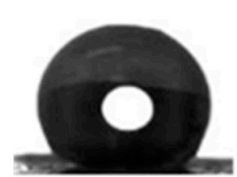

wood
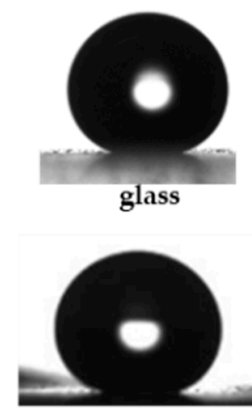

brass

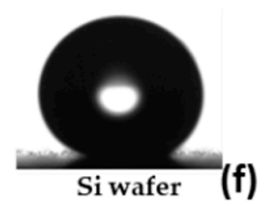

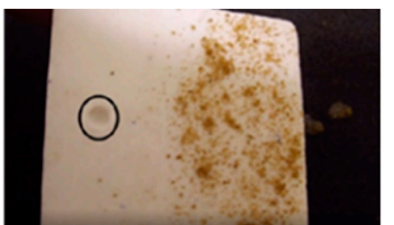
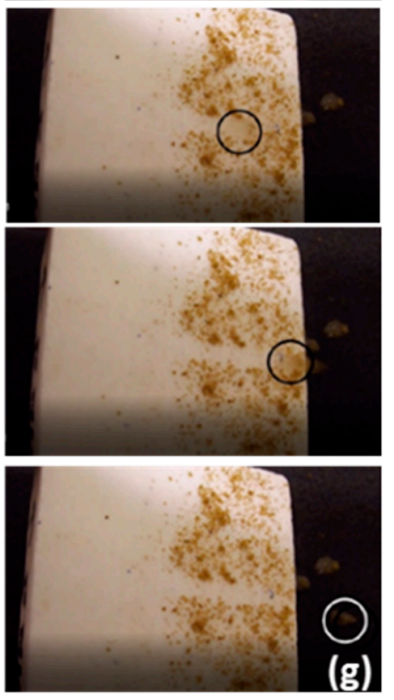

Figure 2. Photographs of water drops on coated (a) marble, (b) wood, (c) silk and (d) brass. (e) SEM image of the surface of coated marble and a side photograph of a water drop. (f) Side photographs of water drops on various coated substrates. (g) The easy/self-cleaning scenario is revealed in the subsequent snapshots from top to bottom. The motion of a water drop is captured by the circles.

The color changes $\left(\Delta E^{*}\right)$ of the substrates due to coating deposition were measured. Glass was excluded from this study as it is transparent to visible light. The following equation was used:

$$
\Delta E^{*}=\sqrt{\left(L_{\mathrm{c}}^{*}-L_{\mathrm{u}}^{*}\right)^{2}+\left(a_{\mathrm{c}}^{*}-a_{\mathrm{u}}^{*}\right)^{2}+\left(b_{\mathrm{c}}^{*}-b_{\mathrm{u}}^{*}\right)^{2}}
$$

where $L^{*}, a^{*}$, and $b^{*}$ are the brightness, the red-green component, and the yellow-blue component of the CIE 1976 scale, respectively. The " $c$ " and " $u$ " subscript characters indicate the coated and uncoated samples, respectively.

The results are summarized in Table 2 and show that the application of the superhydrophobic coating did not have any noticeable optical effect on the aesthetic appearance of marble. Spray deposition gave a somewhat lower $\Delta E^{*}$ (Table 2) compared to the results obtained after brush and dip coating, due probably to the smaller coating uptake reported in Table 1. Regardless of the coating deposition method, all the $\Delta E^{*}$ values on marble specimens were $<3$. Consequently, the application of the coating caused an insignificant color 
change on marble that could not be perceived by the human eye $[17,19,25]$. Likewise, the application of the TEOS-FAS coating had practically no effect on the aesthetic appearance of paper $\left(\Delta E^{*}=0.5\right)$.

Table 2. Color changes $\left(\Delta E^{*}\right)$ calculated using Equation (1).

\begin{tabular}{ccc}
\hline Substrate & Coating Method & $\Delta \boldsymbol{E}^{*}$ \\
\hline Marble & Brush coating & $2.07 \pm 0.23$ \\
Marble & Spray coating & $1.59 \pm 0.97$ \\
Marble & Dip coating & $1.84 \pm 0.23$ \\
Brass & Brush coating & $33.22 \pm 2.66$ \\
Wood & Dip coating & $12.80 \pm 0.63$ \\
Si wafers & Brush coating & $56.72 \pm 0.62$ \\
Paper & Brush coating & $0.50 \pm 0.01$ \\
Silk & Brush coating & $9.70 \pm 0.21$ \\
\hline
\end{tabular}

However, according to the results of Table 2, the application of the TEOS-FAS coating had considerable and visible effects on the colors of silk $\left(\Delta E^{*}=9.70\right)$ and wood $\left(\Delta E^{*}=12.80\right)$, and major effects on the appearances of brass $\left(\Delta E^{*}=33.22\right)$ and Si wafers $\left(\Delta E^{*}=56.72\right)$. These measurements are well beyond the threshold value of 5 , which is the accepted level for the conservation practice of the cultural heritage [17]. A major contribution to the measured $\Delta E^{*}$ originated from the change of the brightness component, $L^{*}$. In Figure 3, a plot of $\Delta E^{*}$ vs. the brightness component of the uncoated, bare substrates $\left(L_{\mathrm{u}}{ }^{*}\right)$ is provided. The results show that, in general, the application of the coating resulted in augmented $\Delta E^{*}$ for substrate materials that corresponded to low values of $L_{\mathrm{u}}{ }^{*}$. The measured $\Delta E^{*}$ decreased with $L_{\mathrm{u}}^{*}$, and the color change became negligible $\left(\Delta E^{*}<3\right)$ for bright materials with $L_{\mathrm{u}}{ }^{*}>90$. This is a general comment and should not be considered as a robust conclusion, as it does not take into account the contributions of the other two coloring components. In fact, the change of the $b^{*}$ component had a significant contribution to the measured $\Delta E^{*}$, particularly in the treatment of silk and wood. On the contrary, the $a^{*}$ component had only a minor contribution to the $\Delta E^{*}$ results of Table 2.

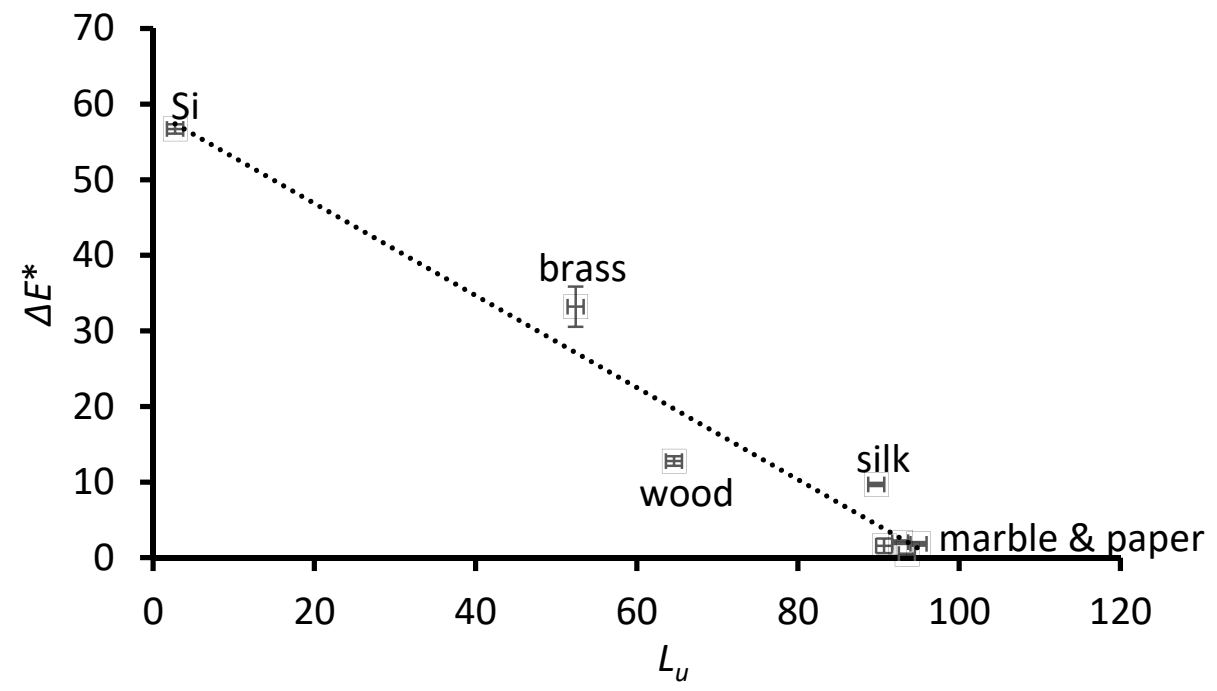

Figure 3. Color change $\left(\Delta E^{*}\right)$ vs. the brightness component $\left(L_{\mathrm{u}}^{*}\right)$ of the uncoated, bare substrates. Data points were fitted with a linear function to guide the eye.

\subsection{Other Properties and Durability of the TEOS-FAS Coating on Marble}

The performance of a material, designed for the protection of natural stone, should be evaluated with respect to the effects of the material on water absorption by capillarity 
and vapor permeability [62]. The durability of the coating is also important. These studies were carried out on marble specimens which were treated using the dip coating method.

The relative reduction of water absorption by capillarity $(R C \%)$ was calculated using the following equation:

$$
R C \%=\left(\frac{m_{u w}-m_{c w}}{m_{u w}}\right) \times 100
$$

where $m_{u w}$ and $m_{c w}$ are the masses of water absorbed by capillarity by the uncoated and coated samples, respectively. As described in Section $2.3 m_{u w}$ and $m_{c w}$ were measured after putting the specimens in contact with liquid water for various periods $t_{\mathrm{i}}$ ranging from 60 to $120 \mathrm{~min}$. The $R C \%$ results are provided in Figure 4 and correspond to a mean value of $74.3 \% \pm 3.4 \%$, which is remarkably close to the corresponding data reported for other superhydrophobic and water-repellent coatings [40,44]. In particular, a composite coating consisted of polysiloxane, an organic fluoropolymer, and silica nanoparticles was deposited on marble and reduced the amount of absorbed water by 75.1\% [40]. Another composite coating consisted of an amino/fluoro-modified polysiloxane and calcium hydroxide nanoparticlesresulted in an $R C \%=73.0$ [44]. The coatings produced in the past $[40,44]$ had similar wetting properties to the TEOS-FAS coating, and they all exhibited superhydrophobicity and water repellency. Based on the contact angle and the $R C \%$ measurements, we can conclude that the three coatings provided comparable protection against the penetration of liquid water into the pore network of the marble stone. For the TEOS-FAS coating, this achievement was obtained without using nanoparticles.

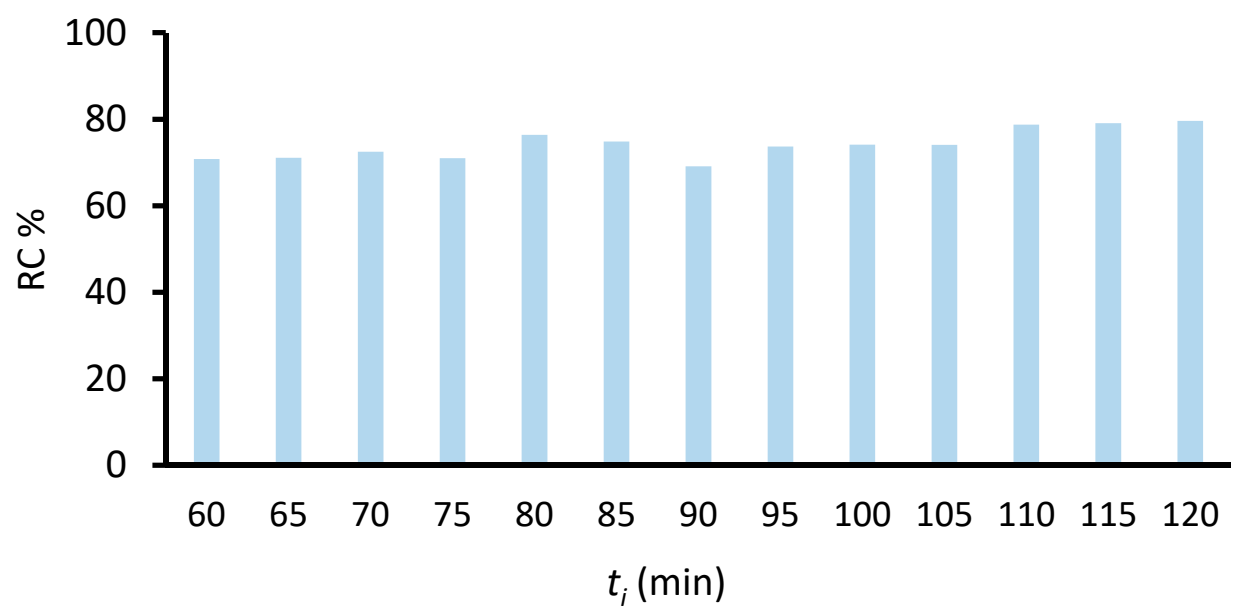

Figure 4. Relative reduction of water absorption by capillarity $(R C \%)$, calculated using Equation $(2)$, vs. treatment time $\left(t_{\mathrm{i}}\right)$ for which the uncoated and coated marble samples had been in contact with liquid water.

The effect of the TEOS-FAS coating on the breathability of marble was quantified using the following equation:

$$
R V P \%=\left(\frac{m_{u v}-m_{c v}}{m_{u v}}\right) \times 100
$$

where, $R V P \%$ is the \% relative reduction of vapor permeability, and $m_{u v}$ and $m_{c v}$ are the masses of water vapor penetrating the uncoated and coated samples, respectively. Using the measured $m_{u v}$ and $m_{c v}$ values and Equation (3), it was calculated that the vapor permeability of marble was reduced by $15.6 \% \pm 3.9 \%$ when the TEOS-FAS material was applied. The ideal but unrealistic scenario would have been to observe no difference between $m_{u v}$ and $m_{c v}$ corresponding to $R V P \%=0$. It has been reported that the average $R V P \%$ on white marble treated by a superhydrophobic and water-repellent composite material was $16.8 \%$ [40]. Consequently, the nanoparticle-free TEOS-FAS and the previously investigated composite material have practically the same effect on the breathability of marble. 
The durability of the structured TEOS-FAS coating was investigated according to four tests, which are described in Figure 5. In particular, CA and SA were measured after leaving coated marble samples in a water bath for various time periods. The results are shown in Figure 5a and suggest that both CA and SA appear to be unaffected by potential swelling or other effects. The durability of the structured coating over a wide range of $\mathrm{pHs}$ is demonstrated in Figure 5b. It can be seen that the wettability of the TEOS-FAS coating was not affected by the $\mathrm{pH}$ of the water drops.
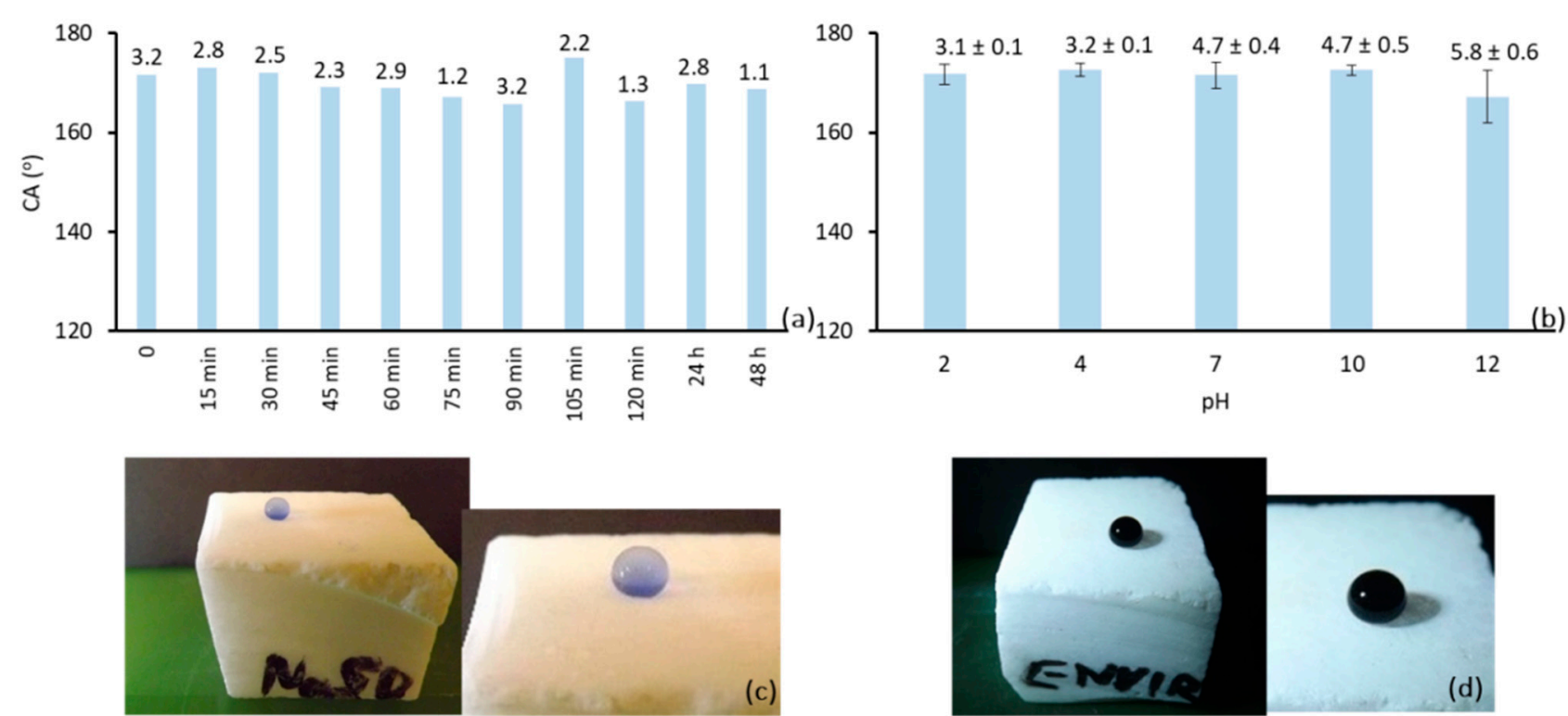

Figure 5. (a) The bars correspond to CA measurements of water drops on coated marbles that were previously immersed in a water bath for various time periods designated in the horizontal axis. The corresponding SA is provided at the top of each bar. (b) The bars correspond to CA measurements of water drops with different pHs. The corresponding SA is provided at the top of each bar. (c) Photographs of water drops on coated marble that was previously immersed in a saturated solution of $\mathrm{Na}_{2} \mathrm{SO}_{4}$. (d) Photographs of water drops on coated marble that was exposed to atmospheric conditions for 70 days.

The photograph in Figure 5c shows a water drop on coated marble that had been treated with a saturated solution of $\mathrm{Na}_{2} \mathrm{SO}_{4}$. Based on the shape of the drop, the photograph demonstrates that coated marble maintained its enhanced hydrophobic character after the specimen was exposed to the corrosive solution of $\mathrm{Na}_{2} \mathrm{SO}_{4}$ [63]. In particular, the surface of the sample of Figure 5 c corresponded to an average CA of $145.3^{\circ} \pm 2.7^{\circ}$, which is just below the $150^{\circ}$ threshold that defines superhydrophobicity. Finally, the photograph of Figure $5 \mathrm{~d}$ was taken after leaving the coated marble specimen outdoors for 70 days. The CAs of drops placed on this coated marble surface were $156.6^{\circ} \pm 2.7^{\circ}$.

It should be noted that the mechanical properties of the TEOS-FAS material and the adhesion of the coating to the substrate were not investigated herein. This research will be conducted in the future.

\section{Conclusions}

The main message of this work is that a TEOS-based material was produced for the protection of marble without using engineering nanoparticles (Figure 1); yet, the material exhibited superhydrophobic and water-repellent properties (Table 1 and Figure 2). Nanoparticles are often used to achieve extreme wetting properties, but their use has potential health and environmental risks. TEOS is very often used in the conservation of stone-built cultural heritage. It should be noted, however, that apart from TEOS, the use of a fluorinated chemical (FAS) was included in the suggested recipe. Fluorine and its anion encompass both beneficial and toxic effects on human health and the environment, and may affect the chemical composition of natural stone [64]. 
It was shown that the TEOS-based material can be used to treat marble and various other substrates (Table 1 and Figure 2), whereas the deposition method does affect the wetting properties (Table 1). The deposition of the material on bright substrates, such as marble and paper, has negligible effects on their colors (Table 2 and Figure 3). Considerable effects on the colors of silk and wood and major effects on the appearances of brass and Si wafers were recorded (Table 2 and Figure 3). After the application of the TEOSbased material on marble, the relative reduction of water absorption by capillarity was of $74.3 \% \pm 3.4 \%$ (Figure 4 ), and the corresponding reduction of vapor permeability was $15.6 \% \pm 3.9 \%$. The durability of the coating was evaluated through various tests, which provided very promising results (Figure 5).

Supplementary Materials: The following are available online at https:/ / www.mdpi.com/2079-641 2/11/2/135/s1, Figure S1: (a) SEM image of bare, uncoated piece of Thassos marble. (b) SEM-EDS analysis of uncoated marble. (b-1) The scan area is designated by the box in the image, Figure S2: XRD analysis of uncoated marble. The major peaks are $A=24.01^{\circ}, B=30.99^{\circ}, C=33.64^{\circ}, D=35.46^{\circ}$, $E=37.38^{\circ}, F=41.25^{\circ}, G=44.97^{\circ}, H=50.65^{\circ}, I=51.12^{\circ}, J=59.92^{\circ}$, Figure S3: Indicative SEM-EDS results for coated marble. The wt.\% percentages are shown in the table. In this case the coating was applied by spraying.

Author Contributions: Conceptualization, I.K.; investigation, F.G.A. and E.P.; writing—original draft preparation, I.K. and E.C.V.; writing-review and editing, D.S.A. and I.K.; supervision, D.S.A. and I.K.; All authors have read and agreed to the published version of the manuscript.

Funding: This research received no external funding.

Institutional Review Board Statement: Not applicable.

Informed Consent Statement: Not applicable.

Data Availability Statement: Data available on request from the authors.

Acknowledgments: The authors would like to thank P.N. Manoudis for his assistance in and contact angle measurements.

Conflicts of Interest: The authors declare no conflict of interest.

\section{References}

1. Karayannidou, E.G.; Achilias, D.S.; Sideridou, I.D. Cure kinetics of epoxy-amine resins used in the restoration of works of art from glass or ceramic. Eur. Polym. J. 2006, 42, 3311-3323. [CrossRef]

2. Wheeler, G. Alkoxysilanes and the Consolidation of Stone; Getty Publications: Los Angeles, CA, USA, 2005.

3. Siegesmund, S.; Weiss, T.; Vollbrecht, A. Natural Stone, Weathering Phenomena, Conservation Strategies and Case Studies: Introduction; Geological Society, Special Publications; Geological Society: London, UK, 2002; Volume 205, pp. 1-7.

4. Karapanagiotis, I.; Hosseini, M. (Eds.) Advanced Materials for the Conservation of Stone; Springer: Cham, Switzerland, 2018.

5. Yao, W.; Li, Y.; Huang, X. Fluorinated poly(meth)acrylate: Synthesis and properties. Polymer 2014, 55, 6197-6211. [CrossRef]

6. Wang, H.; Fang, J.; Cheng, T.; Ding, J.; Qu, L.; Dai, L.; Wang, X.; Lin, T. One-step coating of fluoro-containing silica nanoparticles for universal generation of surface superhydrophobicity. Chem. Commun. 2008, 877-879. [CrossRef] [PubMed]

7. Mosquera, M.J.; De los Santos, D.M.; Rivas, T. Surfactant-synthesized ormosils with application to stone restoration. Langmuir 2010, 26, 6737-6745. [CrossRef] [PubMed]

8. De Ferri, L.; Lottici, P.P.; Lorenzi, A.; Montenero, A.; Salvioli-Mariani, E. Study of silica nanoparticles-polysiloxane hydrophobic treatments for stone-based monument protection. J. Cult. Herit. 2011, 12, 356-363.

9. Illescas, J.F.; Mosquera, M.J. Surfactant-synthesized PDMS/silica nanomaterials improve robustness and stain resistance of carbonate stone. J. Phys. Chem. C 2011, 115, 14624-14634. [CrossRef]

10. Licchelli, M.; Malagodi, M.; Weththimuni, M.L.; Zanchi, C. Water-repellent properties of fluoroelastomers on a very porous stone: Effect of the application procedure. Prog. Org. Coat. 2013, 76, 495-503. [CrossRef]

11. D'Amato, R.; Caneve, L.; Giancristofaro, C.; Persia, F.; Pilloni, L.; Rinaldi, A. Development of nanocomposites for conservation of artistic stones. Proc. Inst. Mech. Eng. N. J. Nanoeng. Nanosyst. 2014, 228, 19-26. [CrossRef]

12. Ugur, I. Surface characterization of some porous natural stones modified with a waterborne fluorinated polysiloxane agent under physical weathering conditions. J. Coat. Technol. Res. 2014, 11, 639-649. [CrossRef]

13. MacMullen, J.; Zhang, Z.; Dhakal, H.N.; Radulovic, J.; Karabela, A.; Tozzi, G.; Hannant, S.; Alshehri, M.A.; Buhé, V.; Herodotou, C.; et al. Silver nanoparticulate enhanced aqueous silane/siloxane exterior facade emulsions and their efficacy against algae and cyanobacteria biofouling. Int. Biodeter. Biodegr. 2014, 93, 54-62. [CrossRef] 
14. Esposito Corcione, C.; Striani, R.; Frigione, M. Hydrophobic photopolymerizable nanostructured hybrid materials: An effective solution for the protection of porous stones. Polym. Compos. 2015, 36, 1039-1047. [CrossRef]

15. Luo, Y.; Xiao, L.; Zhang, X. Characterization of TEOS/PDMS/HA nanocomposites for application as consolidant/hydrophobic products on sandstones. J. Cult. Herit. 2015, 16, 470-478. [CrossRef]

16. Striani, R.; Esposito Corcione, C.; Muia, G.D.A.; Frigione, M. Durability of a sunlight-curable organic-inorganic hybrid protective coating for porous stones in natural and artificial weathering conditions. Prog. Org. Coat. 2016, 101, 1-14. [CrossRef]

17. Pedna, A.; Pinho, L.; Frediani, P.; Mosquera, M.J. Obtaining $\mathrm{SiO}_{2}$-fluorinated PLA bionanocomposites with application as reversible and highly-hydrophobic coatings of buildings. Prog. Org. Coat. 2016, 90, 91-100. [CrossRef]

18. Elhaddad, F.; Carrascosa, L.A.M.; Mosquera, M.J. Long-term effectiveness, under a mountain environment, of a novel conservation nanomaterial applied on limestone from a Roman archaeological site. Materials 2018, 11, 694. [CrossRef]

19. Gherardi, F.; Roveri, M.; Goidanich, S.; Toniolo, L. Photocatalytic nanocomposites for the protection of European architectural heritage. Materials 2018, 11, 65. [CrossRef] [PubMed]

20. Gherardi, F.; Goidanich, S.; Toniolo, L. Improvements in marble protection by means of innovative photocatalytic nanocomposites. Prog. Org. Coat. 2018, 121, 13-22. [CrossRef]

21. Andreotti, S.; Franzoni, E.; Esposti, M.D.; Fabbri, P. Poly(hydroxyalkanoate)s-based hydrophobic coatings for the protection of stone in cultural heritage. Materials 2018, 11, 165. [CrossRef]

22. Roveri, M.; Gherardi, F.; Brambilla, L.; Castiglioni, C.; Toniolo, L. Stone/coating interaction and durability of Si-based photocatalytic nanocomposites applied to porous lithotypes. Materials 2018, 11, 2289. [CrossRef]

23. Lettieri, M.; Masieri, M.; Morelli, A.; Pipoli, M.; Morelli, A.; Frigione, M. Oleo/hydrophobic coatings containing nano-particles for the protection of stone materials having different porosity. Coatings 2018, 8, 429. [CrossRef]

24. Lettieri, M.; Masieri, M.; Pipoli, M.; Morelli, A.; Frigione, M. Anti-graffiti behavior of oleo/hydrophobic nano-filled coatings applied on natural stone materials. Coatings 2019, 9, 740. [CrossRef]

25. Pargoletti, E.; Motta, L.; Comite, V.; Fermo, P.; Cappelletti, G. The hydrophobicity modulation of glass and marble materials by different Si-based coatings. Prog. Org. Coat. 2019, 136, 105260. [CrossRef]

26. Tokarskỳ, J.; Martinec, P.; Kutláková, K.M.; Ovčačíková, H.; Študentová, S.; Ščučka, J. Photoactive and hydrophobic nano$\mathrm{ZnO} /$ poly(alkyl siloxane) coating for the protection of sandstone. Constr. Build. Mater. 2019, 199, 549-559. [CrossRef]

27. Manoudis, P.; Tsakalof, A.; Karapanagiotis, I.; Zuburtikudis, I.; Panayiotou, C. Fabrication of super-hydrophobic surfaces for enhanced stone protection. Surf. Coat. Technol. 2009, 203, 1322-1328. [CrossRef]

28. Manoudis, P.; Karapanagiotis, I.; Tsakalof, A.; Zuburtikudis, I.; Kolinkeová, B.; Panayiotou, C. Superhydrophobic films for the protection of outdoor cultural heritage assets. Appl. Phys. A-Mater. 2009, 97, 351-360. [CrossRef]

29. Tian, S.; Liu, S.; Gao, F.; Ren, J. Preparation and assessment of superhydrophobic organic-inorganic hybrid coatings for conservation of Yungang Grottoes. Mater. Res. Soc. Symp. Proc. 2011, 1319, 333-338. [CrossRef]

30. Chatzigrigoriou, A.; Manoudis, P.N.; Karapanagiotis, I. Fabrication of water repellent coatings using waterborne resins for the protection of the cultural heritage. Macromol. Symp. 2013, 331-332, 158-165. [CrossRef]

31. Facio, D.S.; Mosquera, M.J. Simple strategy for producing superhydrophobic nanocomposite coatings in situ on a building substrate. ACS Appl. Mater. Inter. 2013, 5, 7517-7526. [CrossRef]

32. MacMullen, J.; Radulovic, J.; Zhang, Z.; Dhakal, H.N.; Daniels, L.; Elford, J.; Leost, M.A.; Bennett, N. Masonry remediation and protection by aqueous silane/siloxane macroemulsions incorporating colloidal titanium dioxide and zinc oxide nanoparticulates: Mechanisms, performance and benefits. Constr. Build. Mater. 2013, 49, 93-100. [CrossRef]

33. Karapanagiotis, I.; Pavlou, A.; Manoudis, P.N.; Aifantis, K.E. Water repellent ORMOSIL films for the protection of stone and other materials. Mater. Lett. 2014, 131, 276-279. [CrossRef]

34. Cappelletti, G.; Fermo, P.; Camiloni, M. Smart hybrid coatings for natural stones conservation. Prog. Org. Coat. 2015, 78, 511-516. [CrossRef]

35. Aslanidou, D.; Karapanagiotis, I.; Panayiotou, C. Tuning the wetting properties of siloxane-nanoparticle coatings to induce superhydrophobicity and superoleophobicity for stone protection. Mater. Des. 2016, 108, 736-744. [CrossRef]

36. Helmi, F.M.; Hefni, Y.K. Using nanocomposites in the consolidation and protection of sandstone. Int. J. Conserv. Sci. 2016, 7, 29-40.

37. La Russa, M.F.; Rovella, N.; De Buergo, M.A.; Belfiore, C.M.; Pezzino, A.; Crisci, G.M.; Ruffolo, S.A. Nano-TiO 2 coatings for cultural heritage protection: The role of the binder on hydrophobic and self-cleaning efficacy. Prog. Org. Coat. 2016, 91, 1-8. [CrossRef]

38. Pino, F.; Fermo, P.; La Russa, M.; Ruffolo, S.; Comite, V.; Baghdachi, J.; Pecchioni, E.; Fratini, F.; Cappelletti, G. Advanced mortar coatings for cultural heritage protection. Durability towards prolonged UV and outdoor exposure. Environ. Sci. Pollut. R. 2017, 24, 12608-12617. [CrossRef] [PubMed]

39. Facio, D.S.; Carrascosa, L.A.M.; Mosquera, M.J. Producing lasting amphiphobic building surfaces with self-cleaning properties. Nanotechnology 2017, 28, 265601. [CrossRef]

40. Aslanidou, D.; Karapanagiotis, I.; Lampakis, D. Waterborne superhydrophobic and superoleophobic coatings for the protection of marble and sandstone. Materials 2018, 11, 585. [CrossRef]

41. Mosquera, M.J.; Carrascosa, L.A.M.; Badreldin, N. Producing superhydrophobic/oleophobic coatings on cultural heritage building materials. Pure Appl. Chem. 2018, 90, 551-561. [CrossRef] 
42. Zarzuela, R.; Carbú, M.; Gil, M.L.A.; Cantoral, J.M.; Mosquera, M.J. Ormosils loaded with $\mathrm{SiO}_{2}$ nanoparticles functionalized with Ag as multifunctional superhydrophobic/biocidal/consolidant treatments for buildings conservation. Nanotechnology 2019, 30, 345701. [CrossRef]

43. Karapanagiotis, I.; Ntelia, E. Superhydrophobic paraloid B72. Prog. Org. Coat. 2020, 139, 105224.

44. Chatzigrigoriou, A.; Karapanagiotis, I.; Poulios, I. Superhydrophobic coatings based on siloxane resin and calcium hydroxide nanoparticles for marble protection. Coatings 2020, 10, 334. [CrossRef]

45. Barthlott, W.; Neinhuis, C. Purity of the sacred lotus, or escape from contamination in biological surfaces. Planta 1997, 202, 1-8. [CrossRef]

46. Jeevanandam, J.; Barhoum, A.; Chan, Y.S.; Dufresne, A.; Danquah, M.K. Review on nanoparticles and nanostructured materials: History, sources, toxicity and regulations. Beilstein J. Nanotechnol. 2018, 9, 1050-1074. [CrossRef] [PubMed]

47. Orcel, G.; Phalippou, J.; Hench, L.L. Structural changes of silica xerogels during low temperature dehydration. J. Non. Cryst. Solids 1986, 88, 114-130. [CrossRef]

48. Rubio, F.; Rubio, J.; Oteo, J.L. A FT-IR Study of the hydrolysis of tetraethylorthosilicate (TEOS). Spectrosc. Lett. 1998, 31, 199-219. [CrossRef]

49. Téllez, L.; Rubio, J.; Rubio, F.; Morales, E.; Oteo, J.L. FT-IR study of the hydrolysis and polymerization of tetraethyl orthosilicate and polydimethyl siloxane in the presence of tetrabutyl orthotitanate. Spectrosc. Lett. 2004, 37, 11-31. [CrossRef]

50. Tejedor, M.I.; Paredes, L.; Anderson, M.A. Evaluation of ATR-FTIR spectroscopy as an 'in situ' tool for following the hydrolysis and condensation of alkoxysilanes under rich $\mathrm{H}_{2} \mathrm{O}$ conditions. Chem. Mater. 1998, 10, 3410-3421. [CrossRef]

51. Bogart, K.H.A.; Ramirez, S.K.; Gonzales, L.A.; Bogart, G.R.; Fisher, E.R. Deposition of $\mathrm{SiO}_{2}$ films from novel alkoxysilane/O 2 plasmas. J. Vac. Sci. Technol. A 1998, 16, 3175-3184. [CrossRef]

52. Han, Y.; Wakita, J.; Kurok, S.; Wang, X.; Ando, S. Preparation and characterization of polyimide/fluorinated silicate nano-hybrid thin films with low refractive indices. J. Photopolym. Sci. Technol. 2008, 21, 143-150. [CrossRef]

53. Hering, N.; Schreiber, K.; Riedel, R.; Lichtenberger, O.; Woltersdorf, J. Synthesis of polymeric precursors for the formation of nanocrystalline Ti-C-N/amorphous Si-C-N composites. Appl. Organomet. Chem. 2001, 15, 879-886. [CrossRef]

54. Hozumi, A.; Takai, O. Effect of hydrolysis groups in fluoro-alkyl silanes on water repellency of transparent two-layer hard-coatings. App. Surf. Sci. 1996, 103, 431-441. [CrossRef]

55. Jeong, H.-J.; Kim, D.-K.; Lee, S.-B.; Kwon, S.-H.; Kadono, K. Preparation of water-repellent glass by sol-gel process using perfluoroalkylsilane and tetraethoxysilane. J. Colloid Interf. Sci. 2001, 235, 130-134. [CrossRef] [PubMed]

56. Letellier, P.; Mayaffre, A.; Turmine, M. Drop size effect on contact angle explained by non extensive thermodynamics. Young's equation revisited. J. Colloid. Interf. Sci. 2007, 314, 604-614. [CrossRef] [PubMed]

57. Li, J.; Wang, G.; Meng, Q.; Ding, C.; Jiang, G.; Fang, Y. A biomimetic nano hybrid coating based on the lotus effect and its anti-biofouling behaviors. Appl. Surf. Sci. 2014, 315, 407-414. [CrossRef]

58. Yao, L.; Sathasivam, S.; Song, J.; Crick, C.R.; Carmalt, C.J.; Parkin, I.P. Robust self-cleaning surfaces that function when exposed to either air or oil. Science 2015, 347, 1132-1135.

59. Dirè, S.; Pagani, E.; Babonneau, F.; Ceccato, R.; Carturan, G. Unsupported $\mathrm{SiO}_{2}$-based organic-inorganic membranes. J. Mater. Chem. 1997, 7, 67-73. [CrossRef]

60. Nur, H. Modification of titanium surface species of titania by attachment of silica nanoparticles. Mater. Sci. Eng. B 2006, 133, 49-54. [CrossRef]

61. Manoudis, P.; Karapanagiotis, I.; Tsakalof, A.; Zuburtikudis, I.; Panayiotou, C. Superhydrophobic composite films produced on various substrates. Langmuir 2008, 24, 11225-11232. [CrossRef]

62. Tsakalof, A.; Manoudis, P.; Karapanagiotis, I.; Chryssoulakis, I.; Panayiotou, C. Assessment of synthetic polymeric coatings for the protection and preservation of stone monuments. J. Cult. Herit. 2007, 8, 69-72. [CrossRef]

63. La Russa, M.F.; Ruffolo, S.A.; Belfiore, C.M.; Aloise, P.; Randazzo, L.; Rovella, N.; Pezzino, A.; Montana, G. Study of the effects of salt crystallization on degradation of limestone rocks. Period. Miner. 2013, 82, 113-127.

64. Wang, Z.; Cousins, I.T.; Scheringer, M.; Hungerbuehler, K. Hazard assessment of fluorinated alternatives to long-chain perfluoroalkyl acids (PFAAs) and their precursors: Status quo, ongoing challenges and possible solutions. Environ. Int. 2015, 75, 172-179. [CrossRef] 